Fetal Diagnosis and Therapy

\title{
Does Maternal Body Mass Index Affect the Quantity of Circulating Fetal Cells Available to Use for Cell-Based Noninvasive Prenatal Test in High-Risk Pregnancies?
}

\author{
Sofie Kruckow ${ }^{\mathrm{a}, \mathrm{b}}$ Palle Schelde ${ }^{\mathrm{a}}$ Lotte Hatt ${ }^{\mathrm{a}}$ Katarina Ravn ${ }^{\mathrm{a}}$ \\ Olav Bjørn Petersen ${ }^{c, e}$ Niels Uldbjerg ${ }^{c}$ Ida Vogel ${ }^{d,}$ e Ripudaman Singh ${ }^{a}$ \\ ${ }^{a}$ ARCEDI Biotech ApS, Vejle, Denmark; ${ }^{b}$ Aarhus University, Aarhus, Denmark; ${ }^{c}$ Department of Obstetrics and \\ Gynecology, Aarhus University Hospital, Aarhus, Denmark; ${ }^{d}$ Department of Clinical Genetics, Aarhus University \\ Hospital, Aarhus, Denmark; ${ }^{e}$ Centre for Prenatal Diagnostics, Aarhus University Hospital, Aarhus, Denmark
}

\section{Established Facts}

- Conventional noninvasive prenatal test (NIPT) requires a cell-free fetal DNA fraction above 3-4\% in order to ensure a reliable NIPT result.

- Obesity is associated with a decrease in the fetal fraction and a higher rate of failed NIPT results.

\section{Novel Insights}

- Increasing BMI tends to decrease the quantity of fetal cells available for cell-based NIPT, but not significantly.

- Cell-based NIPT will unlikely be affected by BMI as every sample renders fetal cells.

\section{Keywords}

Cell-based noninvasive prenatal test · Noninvasive prenatal test - Body mass index · Fetal cells in maternal blood

\section{Abstract \\ We present the first study that investigates the effect of ma- ternal body mass index (BMI) on the quantity of circulating fetal cells available to use in cell-based noninvasive prenatal test (cbNIPT). cbNIPT has been proposed as a superior alter-}

\section{KARGER}

E-Mail karger@karger.com www.karger.com/fdt

\section{(c) 2018 The Author(s) \\ Published by S. Karger AG, Basel \\ Karger \\ Open access}

This article is licensed under the Creative Commons AttributionNonCommercial-NoDerivatives 4.0 International License (CC BY NC-ND) (http://www.karger.com/Services/OpenAccessLicense). Usage and distribution for commercial purposes as well as any distribution of modified material requires written permission. native to noninvasive prenatal test from cell-free fetal DNA. Kølvraa et al. [Prenat Diagn. 2016 Dec;36(12):1127-34] established that cbNIPT can be performed on as few as one fetal cell, and Vestergaard et al. [Prenat Diagn. 2017 Nov; 37(11):1120-4] demonstrated that these fetal trophoblast cells could be used successfully in cbNIPT to detect chromosomal and sub-chromosomal abnormalities. This study on 91 pregnant women with high-risk pregnancies suggests that cbNIPT should not be hampered by an increased BMI because every pregnancy, irrespective of the BMI, has rendered
Ripudaman Singh

ARCEDI Biotech ApS

Lysholt Allé 10

DK-7100 Vejle (Denmark)

E-Mail rs@arcedi.com 
fetal cells for downstream genetic analysis. The mean number of fetal cells per sample was 12.6, with a range of 1-43 cells in one sample. ANOVA showed that increasing maternal BMI tends to decrease the number of fetal cells, but not significantly.

(c) 2018 The Author(s)

Published by S. Karger AG, Basel

\section{Introduction}

Noninvasive prenatal testing (NIPT) based on cell-free fetal DNA (cffDNA) circulating in maternal plasma provides effective screening for trisomy 21 (Down syndrome), trisomy 18 (Edward syndrome), and trisomy 13 (Patau syndrome) [1]. However, cffNIPT performance highly depends on the fetal fraction (FF), defined as the proportion of fetal-derived cell-free DNA in the total cellfree DNA component found in maternal plasma. Thus, the FF must exceed 3-4\% to provide a low false negative rate [2]. Several factors including body mass index (BMI) affect the FF. This is illustrated by a lower mean FF among women weighing $60 \mathrm{~kg}(12 \%)$ compared to women weighing $120 \mathrm{~kg}(6 \%)$ [3]. This association is explained by two factors: an increase in the concentration of cell-free maternal DNA and a decrease in the concentration of cffDNA [4]. The increase in the concentration of cell-free maternal DNA is due to enhanced necrosis and apoptosis of adipose tissue in obese pregnant women resulting in the leak of maternal DNA into the circulation [5]. The decrease in cffDNA concentration may be associated with an increased total blood volume in obese women resulting in the dilution of cffDNA [6]. Thus, increasing BMI and obesity are correlated with an increased risk of a failed cffNIPT result. Yared et al. [7] suggested a failure rate of $24.3 \%$ among obese women $(\mathrm{BMI} \geq 30)$ compared with $3.7 \%$ in nonobese women. Consequently, there are limitations in the use of NIPT technology in the population of obese pregnant women.

Emerging technologies that source intact fetal cells from maternal blood have been proposed as superior alternatives to cffNIPT. These technologies are called cellbased noninvasive prenatal tests (cbNIPT). In conventional cffNIPT, the DNA is fragmented and contaminated with maternal DNA making it difficult to detect small copy number variations in the fetal genome. Since fetal cells encompass the uncontaminated fetal genome, cbNIPT paves the way for progress in noninvasive prenatal testing [8]. Vestergaard et al. [9] previously demonstrated that aneuploidies and even sub-chromosomal aberrations can be detected using this cbNIPT technology.
However, the influence of BMI on the number of fetal cells and cbNIPT technology has not yet been explored. The objective of this study was to investigate the relationship between maternal BMI and the number of fetal cells in venous blood samples.

\section{Methods}

The study was approved by the Danish Research Ethics Committee (project ID: S-20070045). The data set consisted of 91 blood samples drawn sequentially as part of a larger validation study of the cbNIPT method conducted by ARCEDI Biotech ApS, a Danish biotech company that holds proprietary technology for the enrichment and analysis of rare fetal extravillous trophoblast cells from pregnant women's blood. Pregnant women at high risk of trisomy 21 ( $>1: 300$ in the Danish combined first-trimester screening program) who opted for invasive testing in the Central Region of Denmark were asked to participate. A total of $30 \mathrm{~mL}$ of blood was drawn from each woman. Blood processing, fetal cell enrichment as well as fetal cell staining and scanning was done as previously described $[8,10]$. In short, red blood cells were lysed; the white blood cells were incubated with a fetal cell-specific antibody cocktail [8]. After incubation, the cells were applied to Miltenyi MS columns where fetal cells were enriched and stained using a cocktail of cytokeratin antibodies. Retained cells were eluted from the column and spread on glass slides. A fluorescence scanner (MetaSystems) located enriched and cytokeratin-stained fetal cells on the slides and final visual validation was performed by trained personnel. This method provides a high fetal cell specificity, which was previously validated and published by Kølvraa et al. in 2016 [8]. For the statistical analysis, the 91 subjects were subcategorized into four BMI weight classes according to WHO classification $(<18.5=$ underweight; $18.6-24.9=$ normal; $25.0-29.9=$ overweight; $30.0-39.0=$ obese $)$.

\section{Results}

The 91 pregnant women had a mean BMI of 23.9, which ranged between 17 and 38.7. The mean number of fetal cells per sample ( $30 \mathrm{~mL}$ of whole blood) was 12.6 , with a range of 1-43 cells in one sample. The number of fetal cells, mean, median, range, and standard deviation in different groups are shown in Table 1.

Fetal cell numbers in the four BMI groups are distributed as illustrated in the scatter plot (Fig. 1). The mean number of fetal cells per sample was 18.9 in the underweight group, 13.0 in the normal weight group, 10.1 in the overweight group, and 10.6 in the obese group. We did an analysis of variance (ANOVA), comparing the mean number of fetal cells in the four groups. Even though the decrease in the number of fetal cells with increased BMI was observed, the variance among the BMI groups was not statistically significant $(p=0.14)$. We also performed 
Fig. 1. The scatter plot shows the distribution of fetal cells in 91 pregnant women. Each BMI subgroup is marked with a vertical line. Extreme values of fetal cell numbers are more frequent in the underweight and normal weight group, and a decrease in the number of fetal cells trends with an increasing BMI. Md, median.

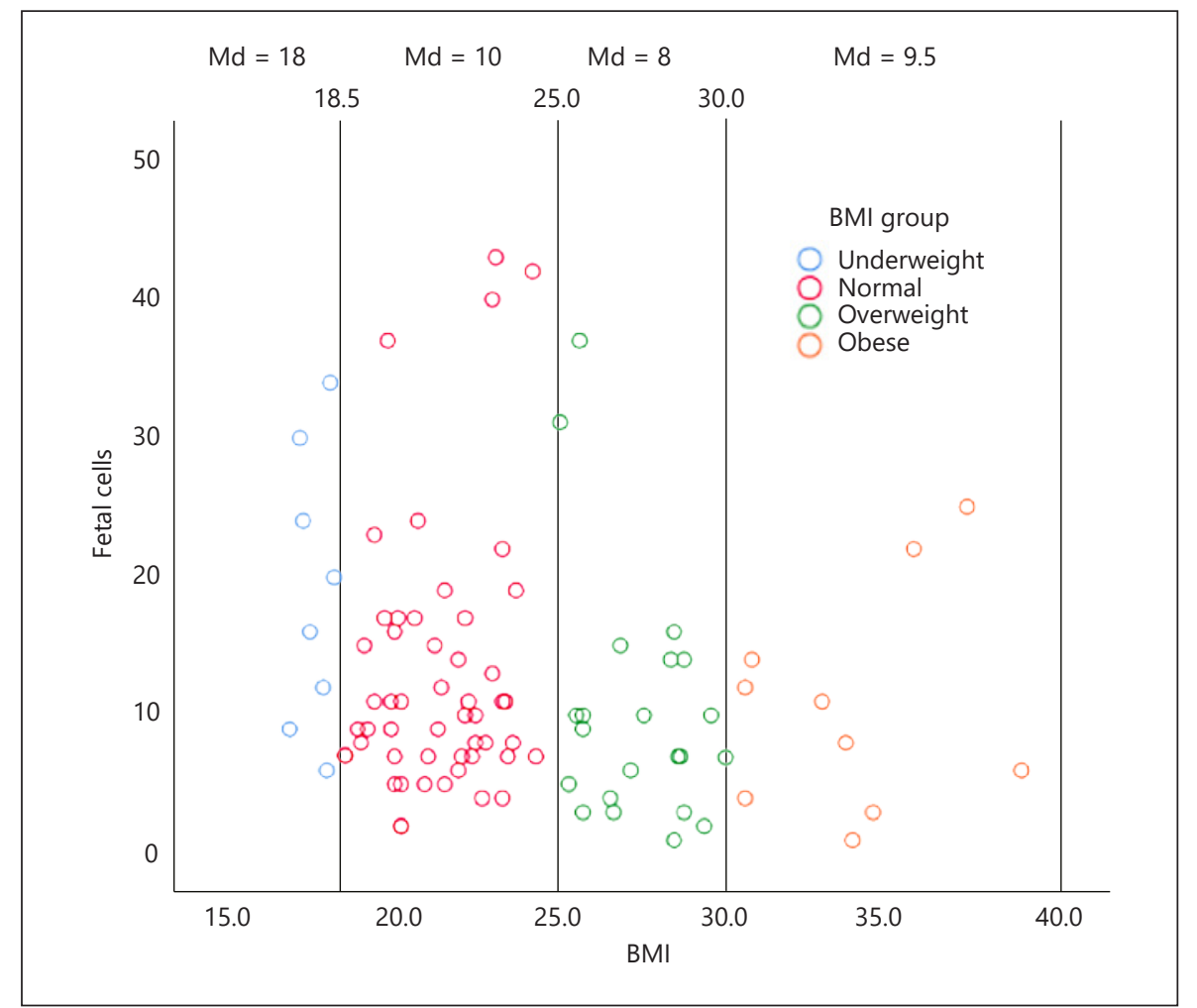

Table 1. The mean and median number of fetal cells in four BMI groups

\begin{tabular}{lccccrr}
\hline & Count, $n$ & Fetal cells & Mean & Median & Range & SD \\
\hline Underweight & 8 & 151 & 18.9 & 18.0 & $6-34$ & 10.0 \\
Normal & 51 & 663 & 13.0 & 10.0 & $2-43$ & 9.7 \\
Overweight & 22 & 224 & 10.2 & 8.0 & $1-37$ & 8.9 \\
Obese & 10 & 106 & 10.6 & 9.5 & $1-25$ & 8.0 \\
\hline
\end{tabular}

$\mathrm{SD}$, standard deviation.

the Kruskal-Wallis nonparametric test, and the association of BMI with fetal cell numbers was still not significant $(p=0.07)$.

\section{Discussion}

The present study on fetal cell numbers from 91 highrisk pregnancies suggests that increasing maternal BMI tends to decrease the number of fetal cells in a venous blood sample, but not significantly. In particular, the underweight and normal weight women present outliers with very high fetal cell numbers. No data was obtained from women who declined to participate. Consequently, our cohort may be affected by selection bias. However, we find this unlikely since the distribution of BMI in our data is similar to the distribution of BMI among Danish women in the age range of 16-44 years. In our study, 35.2\% had a BMI $\geq 25$ compared to $35.5 \%$ in the general population according to The Danish National Health Survey $2017^{1}$ [11]. The lack of statistical significance of the cor-

1 The Danish National Health Survey was funded by The Capital Region,
Region Zealand, The South Denmark Region, The Central Denmark Region,
The North Denmark Region, The Ministry of Health and the National Institute of Public Health, University of Southern Denmark. 
relation between fetal cell numbers and BMI might be due to the small sample size. There were only 8 and 10 samples in the underweight and obese groups, respectively. Having more samples in these two groups could lead to an increase in the statistical power of the test.

Importantly, however, none of the samples, not even in the obese group, came out with 0 fetal cells, which otherwise could impact cbNIPT since at least one fetal cell is needed for downstream genetic analysis. Kølvraa et al. [8] demonstrated, that cbNIPT can be performed on as few as one fetal cell using whole genome amplification, array comparative genomic hybridization, and next-generation sequencing. Furthermore, the study by Vestergaard et al. [9] demonstrated that these fetal trophoblast cells could be used successfully in cbNIPT to detect chromosomal and sub-chromosomal abnormalities. When seen through the light of these previous results, the current data suggests that cbNIPT should not be hampered by an increased BMI because every pregnancy, irrespective of the BMI, has rendered fetal cells for downstream genetic analysis. The current data is from high-risk pregnancies. We have previously investigated if the number of fetal cells is different between high-risk and low-risk pregnancies and found that the mean and distribution of fetal cells is similar in two groups (data not published). This also implies that the current data on the BMI and fetal cells from high-risk pregnancies could very well be transferable to the low-risk population.

ARCEDI Biotech is currently conducting a study on high-risk pregnancies that compares the results from cffNIPT, cbNIPT, and chorionic villi samples to validate the performance of cbNIPT.

\section{Disclosure Statement}

The experiments described in this article were performed in and funded by the private company ARCEDI Biotech ApS, where the authors Sofie Kruckow, Ripudaman Singh, Palle Schelde, Lotte Hatt, and Katarina Ravn are employed.

\section{References}

1 Norton ME, Brar H, Weiss J, Karimi A, Laurent LC, Caughey AB, et al. Non-Invasive Chromosomal Evaluation (NICE) Study: results of a multicenter prospective cohort study for detection of fetal trisomy 21 and trisomy 18. Am J Obstet Gynecol. 2012 Aug;207(2):137.e1-8.

2 Scott FP, Menezes M, Palma-Dias R, Nisbet D, Schluter P, da Silva Costa F, et al. Factors affecting cell-free DNA fetal fraction and the consequences for test accuracy. J Matern Fetal Neonatal Med. 2018 Jul;31(14):1865-72.

3 Ashoor G, Syngelaki A, Poon LC, Rezende JC, Nicolaides KH. Fetal fraction in maternal plasma cell-free DNA at 11-13 weeks' gestation: relation to maternal and fetal characteristics. Ultrasound Obstet Gynecol. 2013 Jan; 41(1):26-32.

4 Canick JA, Palomaki GE, Kloza EM, LambertMesserlian GM, Haddow JE. The impact of maternal plasma DNA fetal fraction on next generation sequencing tests for common fetal aneuploidies. Prenat Diagn. 2013 Jul;33(7): $667-74$
5 Haghiac M, Vora NL, Basu S, Johnson KL Presley L, Bianchi DW, et al. Increased death of adipose cells, a path to release cell-free DNA into systemic circulation of obese women. Obesity (Silver Spring). 2012 Nov;20(11): 2213-9.

6 Wang E, Batey A, Struble C, Musci T, Song K, Oliphant A. Gestational age and maternal weight effects on fetal cell-free DNA in maternal plasma. Prenat Diagn. 2013 Jul;33(7):6626.

7 Yared E, Dinsmoor MJ, Endres LK, Vanden Berg MJ, Maier Hoell CJ, Lapin B, et al. Obesity increases the risk of failure of noninvasive prenatal screening regardless of gestational age. Am J Obstet Gynecol. 2016 Sep;215(3): 370.e1-6.

8 Kølvraa S, Singh R, Normand EA, Qdaisat S, van den Veyver IB, Jackson L, et al. Genomewide copy number analysis on DNA from fetal cells isolated from the blood of pregnant women. Prenat Diagn. 2016 Dec;36(12): 1127-34.
9 Vestergaard EM, Singh R, Schelde P, Hatt L, Ravn K, Christensen R, et al. On the road to replacing invasive testing with cell-based NIPT: five clinical cases with aneuploidies, microduplication, unbalanced structural rearrangement, or mosaicism. Prenat Diagn. 2017 Nov;37(11):1120-4.

10 Hatt L, Brinch M, Singh R, Møller K, Lauridsen $\mathrm{RH}$, Uldbjerg $\mathrm{N}$, et al. Characterization of fetal cells from the maternal circulation by microarray gene expression analysis-could the extravillous trophoblasts be a target for future cell-based non-invasive prenatal diagnosis? Fetal Diagn Ther. 2014;35(3):218-27.

11 The Ministry of Health and the National Institute of Public Health, University of Southern Denmark. (2018). The Danish National Health Survey. Retrieved from: http://proxy. danskernessundhed.dk/SASVisualAnalyticsViewer/VisualAnalyticsViewer_guest.jsp? reportName $=$ Overvaegt\&amp;reportPath $=/$ Produktion/Danskernes_Sundhed/ 